\title{
Consumer perception of probiotic yogurt: Performance of check all that apply (CATA), projective mapping, sorting and intensity scale
}

\author{
A.G. Cruz ${ }^{\text {a,b,* }}$, R.S. Cadena ${ }^{\text {a }}$, W.F. Castro ${ }^{\text {c }}$, E.A. Esmerino ${ }^{\text {a }}$, J.B. Rodrigues ${ }^{\text {a }}$, L. Gaze ${ }^{\text {d }}$, J.A.F. Faria ${ }^{\text {a }}$, M.Q. Freitas ${ }^{\text {d }}$, \\ R. Deliza ${ }^{\mathrm{e}}$, H.M.A. Bolini ${ }^{\mathrm{a}}$ \\ a Universidade Estadual de Campinas (UNICAMP), Faculdade de Engenharia de Alimentos (FEA), Cidade Universitária Zeferino Vaz, 13083-862 Campinas, São Paulo, Brazil \\ b Instituto Federal de Educação, Ciência e Tecnologia do Rio de Janeiro (IFRJ), Mestrado Profissional em Ciência e Tecnologia de Alimentos (PGCTA), Rua Senador Furtado, 171, Maracanã, \\ 20270-021 Rio de Janeiro, Brazil \\ ' Instituto Federal de Educação, Ciência e Tecnologia de São Paulo (IFSP), Avenida C-1, 250, Campus Barretos, 14781502 São Paulo, Brazil \\ d Universidade Federal Fluminense (UFF), Faculdade de Medicina Veterinária, Niterói 24230-340, Rio de Janeiro, Brazil \\ e Empresa Brasileira de Pesquisa Agropecuária (EMBRAPA), Centro Nacional de Pesquisa de Tecnologia Agroindustrial de Alimentos (CTAA), Av. das Américas, 29.501, Guaratiba, \\ CEP 23020-470 Rio de Janeiro, RJ, Brazil
}

\section{A R T I C L E I N F O}

Article history:

Received 12 November 2012

Accepted 26 July 2013

\section{Keywords:}

Check all that apply

Projective mapping

Sorting

Intensity scale

Consumer perception

Probiotic yogurts

\begin{abstract}
A B S T R A C T
The performance of check-all-that-apply (CATA), projective mapping, sorting and intensity scales was assessed for determining consumer perception of probiotic yogurts, two prototypes added with glucose oxidase, a potential oxygen scavenger and 04 commercial brands available in the Brazilian market. Each sensory methodology was tested by administrating the tests to 30 regular consumers of the product. Napping and CATA did not provide adequate discrimination of the samples while better results were noted for sorting and intensity scales, separating the yogurts containing glucose oxidase from the commercial probiotic yogurt. Sensory methodologies using consumer responses present potential options for the characterization of food matrices with multiple sensory sensations, such as probiotic yogurt.
\end{abstract}

(C) 2013 Elsevier Ltd. All rights reserved.

\section{Introduction}

During the development and improvement of food products, companies should strive to understand consumers' wants and needs, as well as their perception of their food products, in order to assure the products' success (Varela, Ares, Gimenez, \& Gambaro, 2010). This means that companies should gain a deep understanding of how consumers perceive products, how their needs are shaped and influenced and how they make product choices based on their needs (Ares, Giménez, Barreiro, \& Gámbaro, 2010c).

In traditional sensory studies, consumer tests focus on hedonic measure while the quantitative determination of the product's sensory properties is done by sensory profiling techniques, normally with a trained group of subjects, by quantitative descriptive analysis (QDA), a well established descriptive sensory methodology used on several food products, including dairy foods (Allgeyer, Miller, \& Lee, 2010; Cadena, Cruz, Faria, \& Bolini, 2012; Gonzalez, Adhikari, \&

\footnotetext{
* Corresponding author at: Universidade Estadual de Campinas (UNICAMP), Faculdade de Engenharia de Alimentos (FEA), Cidade Universitária Zeferino Vaz, 13083-862 Campinas, São Paulo, Brazil. Tel.: + 551935214016 .

E-mail address: food@globo.com (A.G. Cruz).
}

Sancho-Madriz, 2011). The high specialization of descriptive panels allows obtaining very detailed, robust, consistent and reproducible results, stable in time and within a certain sensory space (Moussaoui \& Varela, 2010).

However, creating and maintaining a well-trained, calibrated sensory panel can be quite expensive. Small food companies usually cannot afford it, and it could even mean a significant expense for large companies if they have a wide range of products that require various panels working in parallel (Valentin, Chollet, Lelievre, \& Abdi, 2012). Furthermore, the training stage can be relatively long, as it should be detailed and extensive, varying between 10 and $120 \mathrm{~h}$, depending on the range and complexity of the sample set (Lawless \& Heymann, 2010). Another important fact is that companies, mainly the small and medium-sized ones, do not have the time, or resources, to maintain a trained panel for evaluating a specific product. So they need to look for other alternatives to obtain information on the sensory characteristics of their food product, even in a general context (Bruzzone, Ares, \& Giménez, 2012). In this context, sensory methodologies which use consumer responses can be a valuable option for obtaining a global perception of the food product, as they consume little time and usually require only one consumer test. Then, appropriate statistical data treatment allows the determination of important relationships between sensory attributes and samples (Varela \& Ares, 2012). 
Yogurt is a very popular product in most countries, regardless of their human development index (Huertas, 2012). It is considered a healthy product and enjoys a positive reputation in the minds of consumers (Annuziata \& Vecchio, 2013; Granato et al., 2010). Recently, the addition of probiotic bacteria and prebiotic ingredients to yogurt has contributed to increase these characteristics even more, making the product one of the main representatives of the functional food categories (Cruz et al., 2013). From the technological viewpoint, yogurt results from the production of lactic acid during the bacterial fermentation of lactose by the starter culture. The metabolic activity of fermentation varies greatly depending on the operational parameters, namely time and temperature, used during the fermentation process, ingredients added for the fortification of the milk base (Lucey, 1998) and the conditions used during the cooling stage and storage of the product in commercial establishments (Ferdouse et al., 2013). The addition of probiotic cultures increases the complexity of the product with regard to its sensory and structural characteristics because of the diversity of the proteolytic activity and production of additional acid metabolites, such as acetic acid produced by strains of the genus Bifidobacterium and by some Lactobacillus acidophilus strains (Gomes et al., 2011). Finally, the addition of fruit pulps and sweeteners contributes for the establishment of multiple, interconnected sensory sensations.

It should be interesting to investigate the use of sensory methodologies using consumer responses in the characterization of probiotic yogurts. Indeed, yogurts are multidimensional product in terms of sensory attributes and from the technological viewpoint they are easily manufactured. Additionally, they are a common part of the line of products of dairies of different sizes, small, medium or big factories, with different levels of control about the operational parameters. Recently, the performance of sorting, projective mapping, intensity scales and checkall-that-apply questions using orange-flavored powdered juice drinks has been published (Ares, Varela, Rado, \& Giménez, 2011c).

In this sense, the objective of this study was to evaluate the consumer perception of probiotic yogurt using four different consumer profiling techniques: sorting, projective mapping, check-all-that-apply questionnaire (CATA) and intensity scale. Six yogurts were used: two prototype yogurts with different concentrations of glucose oxidase, a potential oxygen scavenger and four commercial strawberry-flavored probiotic yogurts, established formulations, available in the Brazilian market.

\section{Material and methods}

\subsection{Prototype and commercial probiotic yogurts}

Six different strawberry-flavored probiotic yogurts were used in this study: four commercial yogurts (PC1, PC2, PC3, PC4) of different Brazilian commercial brands marked along Brazilian territory and two prototype yogurts (GOX1 and GOX1) produced with the following cultures: Streptococcus thermophilus TA 040, Lactobacillus delbrueckii ssp. bulgaricus LB 340 with Bifidobacterium longum BL 05 and L. acidophilus La14 (6,6, 7,7 log CFU/g respectively, Danisco, São Paulo, Brazil). Glucose oxidase ( 250 and $500 \mathrm{ppm}$ ) was also added to the prototype probiotic yogurts since it is a potential oxygen scavenging system that guarantees the survival of probiotic bacteria. Previous studies performed with these yogurts added with other glucose oxidase levels indicated a high level of organic acid (lactic and acetic acid) and aroma compounds (diacetyl and acetaldehyde) as well as increased proteolysis (Cruz et al., 2010, 2012a,b; Cruz et al., 2013). In addition, they were considered similar towards overall acceptance with commercial plain products in hedoni test performed with 120 consumers (Cruz et al., 2011, 2012c). The gross composition as well as the probiotic cultures added are showed in Table 1.

\subsection{Consumer test}

Thirty regular yogurt consumers aged 17 to 40 years, being $60 \%$ females and $40 \%$ males, $50 \%$ with high school and $15 \%$ with elementary
Table 1

Nutrient composition of probiotic yogurts.

\begin{tabular}{llll}
\hline Yogurt & Protein & Fat & Probiotic bacteria \\
\hline GOX1 & 3.3 & 2.7 & B. longum Bl05/L.acidophilus La14 \\
GOX2 & 3.5 & 2.8 & B. longum Bl05/L.acidophilus La14 \\
PC1 & 2.7 & 1.6 & L. casei defensis \\
PC2 & 2.5 & 3.4 & B. animalis DN173010 \\
PC3 & 2.8 & 3.0 & B. lactis/L. acidophilus \\
PC4 & 4.3 & 3.0 & B. lactis/L. acidophilus \\
\hline
\end{tabular}

g/100 g yogurt. GOX1, GOX2 - yogurts added with glucose oxidase (250 and 500 ppm, respectively, nutrient levels determined by standardized methodology). PC1, PC2, PC2, PC4 - values in accordance with label. All yogurts sweetened with sucrose and added with artificial strawberry pulp.

school participated in the test, done sequentially on different days. They were randomly recruited at the Campinas State University (UNICAMP) and, to avoid recruiting too many graduate students, employees were also invited to participate. The inclusion criteria were at least weekly consumption of yogurt and no allergy to milk.

The tests were fulfilled in a controlled environment (temperature $=$ $20{ }^{\circ} \mathrm{C}$ ) and $20 \mathrm{~mL}$ of the yogurts was served at a temperature of $5{ }^{\circ} \mathrm{C}$ using plastic cups codified with 3 digits. Before the test was done, all participants read and signed a free and informed consent form. After tasting each sample, all participants were asked to eat a cream-cracker biscuit and drink some water. The first-order carry-over effect was balanced by our own design (MacFie, Bratchell, Greenhoff, \& Vallis, 1989). The test was approved by the Research Ethics Committee of UNICAMP's School of Medical Sciences under protocol number 295/2008.

\subsection{Check all that apply (CATA), sorting, napping and intensity scales}

CATA, sorting, projective mapping (napping), and intensity scale were performed using standardized procedures. The basics about the tests and ways to perform them have been extensively reported and, recently, two excellent reviews have become available (Valentin et al., 2012; Varela \& Ares, 2012).

Therefore, it is unnecessary to go into all the details covered by the tests since there was no deviation from the traditional procedure. For the sorting and napping, all samples were presented a single time for each consumer; for both a descriptive step was inserted after the formation of the groups among the samples (in the case of sorting) and after the positioning of the samples on the A4 sheet (projective mapping).

For CATA and the intensity scale, the samples were presented in a monadic and balanced form for each consumer. For the former, the consumers were asked to check all the attributes which applied to describe the samples. The terms used in the CATA questionnaire and descriptive scales were taken from a recent study involving the sensory profile of commercial yogurts available in Brazil (Moraes \& Bollini, 2010). The intensity scales used were unstructured $10 \mathrm{~cm}$ intensity scales, anchored with null and high, for each of the samples. The following attributes were used: appearance (pink color, red points, presence of bubbles, presence of grains, apparent viscosity), aroma (strawberry aroma, milk aroma, yogurt aroma, acid aroma, sweet aroma), taste (acid taste, sweet taste, strawberry flavor, bitter taste) and texture (viscous). Although in a first view, apparent viscosity can be of complicated measure by consumers, preliminary test indicated the adequacy of inclusion of this attribute, as the samples presented considerable difference in a visual form with relation of texture.

\subsection{Statistical analysis}

Analysis of variance (ANOVA) was used for analyzing the intensity scale using consumers and samples as a fixed source of variation. Additionally, an analysis of the main components (PCA) was done using a correlation matrix with the means of the samples. 
Hierarchical cluster analysis (HCA) was also performed to find group of samples with similar sensory characteristics in each methodology, having as input samples' coordinates in the first and second dimension of the sensory maps produced by each technique, considering Euclidean distances (dissimilary) and Warld's techniques (agglomeration method) and automatic truncation (Moussaoui \& Varela, 2010).

Multiple factor analysis (MFA) was used for analyzing data obtained at the sorting, napping and CATA (Ares, Varela, Rado \& Gimenez, 2011b, 2011c, Moussaoui \& Varela, 2010). It involved the establishment of a matrix where the rows were the yogurts (6 lines) and the columns were the attributes used by the consumers to describe the samples. A qualitative analysis of the terms used was done previously to avoid superposition and similar terms were joined. The analysis consisted of the terms cited by $20 \%$ of the consumers. Next, the terms used for describing each sample were counted.

A second MFA was done to obtain a comparison of the methodologies used, assessing the positioning of the products in a single sensory map. This involved the construction of a 6-row matrix (yogurts) with four groups of columns which corresponded to the data used by the consumers for describing the samples in each methodology. The similarity/correlation coefficient $\mathrm{Rv}$ was used as a quantitative measure of this correspondence (Ares, Varela, Rado, \& Gimenez, 2011b; Moussaoui \& Varela, 2010). All statistical analyses were done by the software XLSTAT for Windows version 2012.5 (Adinsoft, Paris, France).

\section{Results and discussion}

\subsection{Sensory maps}

Figs. 1-4(a,b) show the sensory maps obtained with the sensory techniques, namely sorting, napping, CATA and intensity scales. CATA and napping did not proportionate a good discrimination of the samples, that is, discriminate the prototype yogurts (GOX1 and GOX2) from the commercial probiotic yogurts (PC1,PC2,PC3 and PC4), as it could be noted in a visual way in the sensory map of the samples by
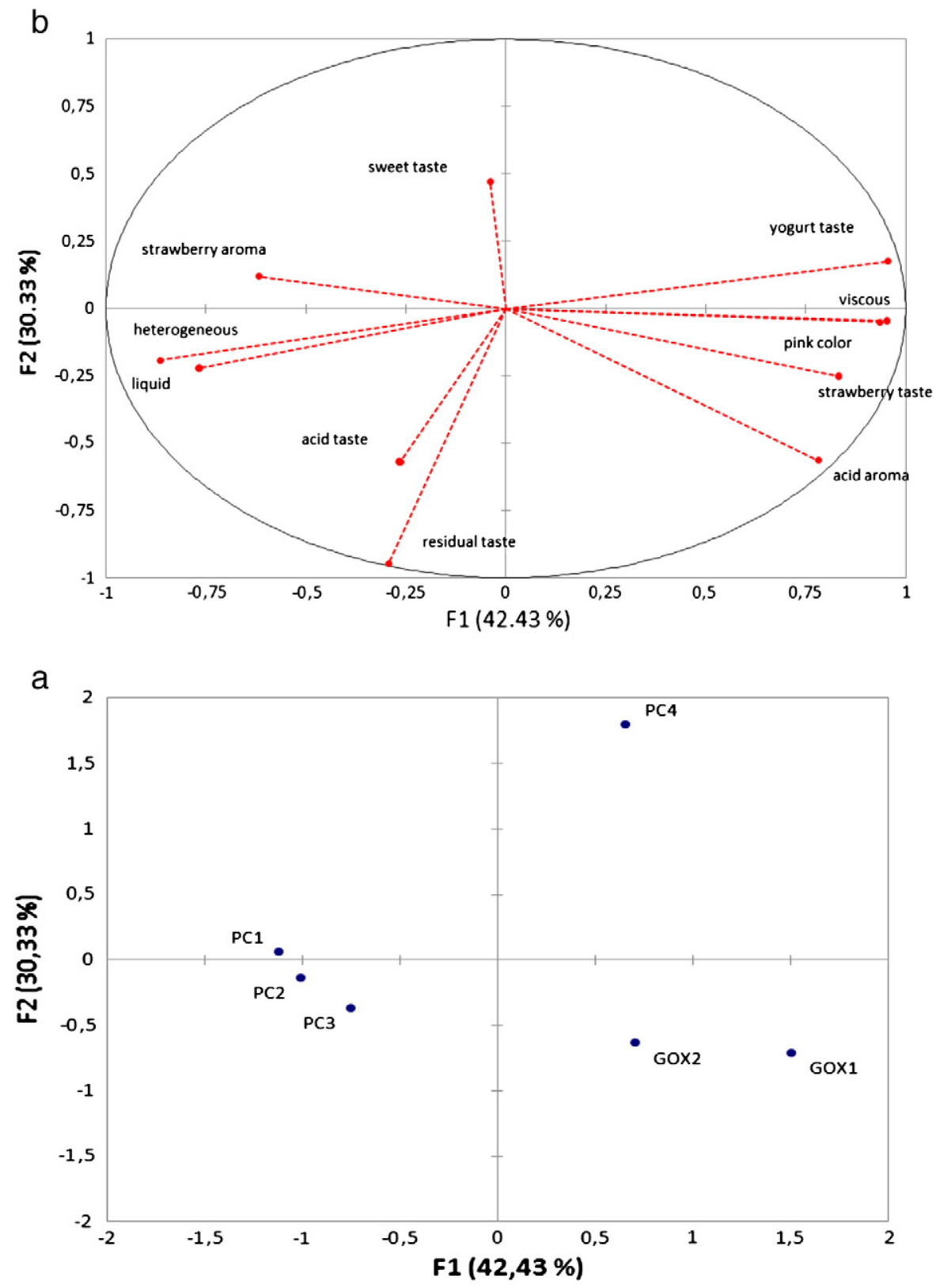

Fig. 1. Representation of the six strawberry probiotic yogurts (b) and the terms used to describe the samples (a), in the first two dimensions of the MFA of data from sorting. 
the similar positions occupied. For CATA, Yogurt PC4 and PC3 came closest to the prototype yogurts GOX1 and GOX2. Projective mapping resulted in a more different configuration, placing yogurt GOX2 close to the commercial yogurts PC1, PC2 and PC3 and yogurt GOX1 close to the yogurt PC4. The use of multiple factor analysis for napping, sorting and CATA explained in two dimension values between $70 \%$ and $80 \%$, regardless of the methodology used.

According to sorting the samples PC1, PC2 and PC3 were characterized by an acid taste, strawberry aroma, fluid and heterogeneous appearance; yogurts GOX1 and GOX2 were characterized by an acid aroma, strawberry taste, pink color, yogurt taste and viscous; and yogurt PC4 was characterized by a sweet taste. Curiously, strawberry aroma and strawberry taste were placed at the opposite sides of the sorting map, that can be related to the nutrient composition of the yogurts; GOX1 and GOX2 present increased protein level compared with yogurts PC1, PC2 and PC3 which is responsible for less intense flavor intensity, in particular fruity notes (Saint-Eve, Lévy, Martin, \& Souchon, 2006).
For projective mapping (Fig. 2,a,b), strawberry aroma and taste, sweet taste and presence of grains were attribute characteristics of the samples PC1, PC2, PC3 and GOX2; yogurt taste and acid taste were characteristic of the sample GOX1; and viscosity, bitter taste and yogurt aroma were characteristic of the sample PC4. HCA confirmed the observed groups for each sensory methodology (Fig. 5a-d) showing that, only sorting and intensity scales were able to separate totally GOX1 and GOX2 from the commercial probiotic yogurts (PC1, PC2, PC3, PC4).

Indeed, the addition of probiotic bacteria in yogurt can introduce different sensory sensations - sometimes called probiotic flavor - which can be a result in decreased sensory acceptance of the product; in addition it is important to know the similarities and differences among prototype as commercial products as probiotic yogurts added with glucose oxidase towards the established formulations of the commercial probiotic yogurts used in this study, which present excellent appreciation by the consumers. It is also relevant to emphasize that all the commercial brands are well known for Brazilian consumers, being commercialized

\section{b}

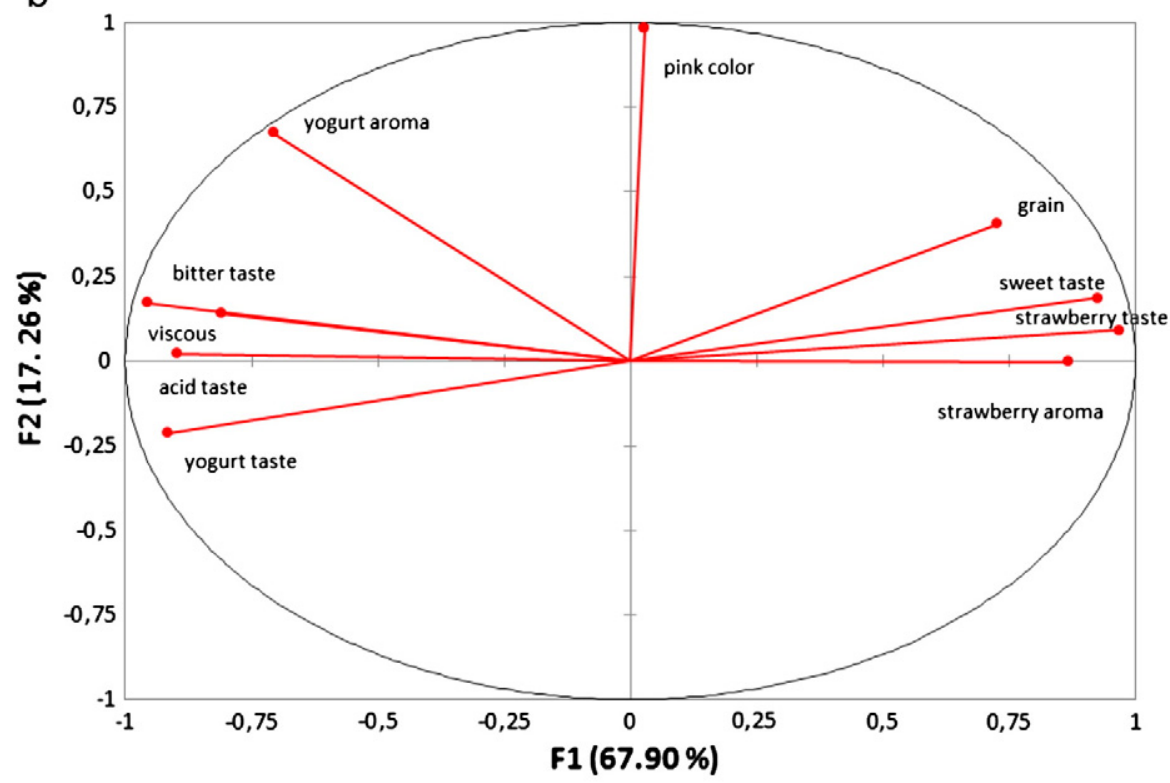

a

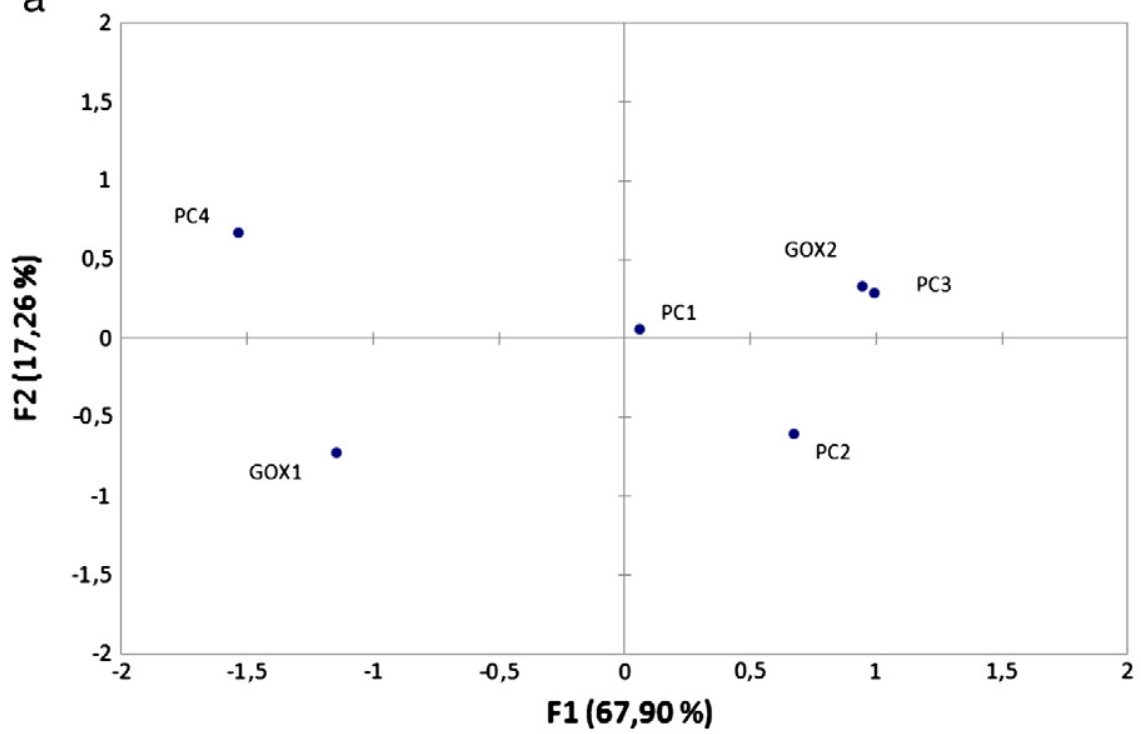

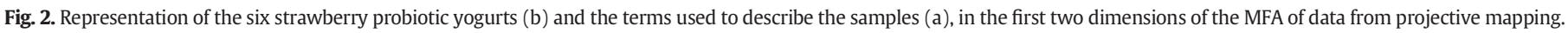



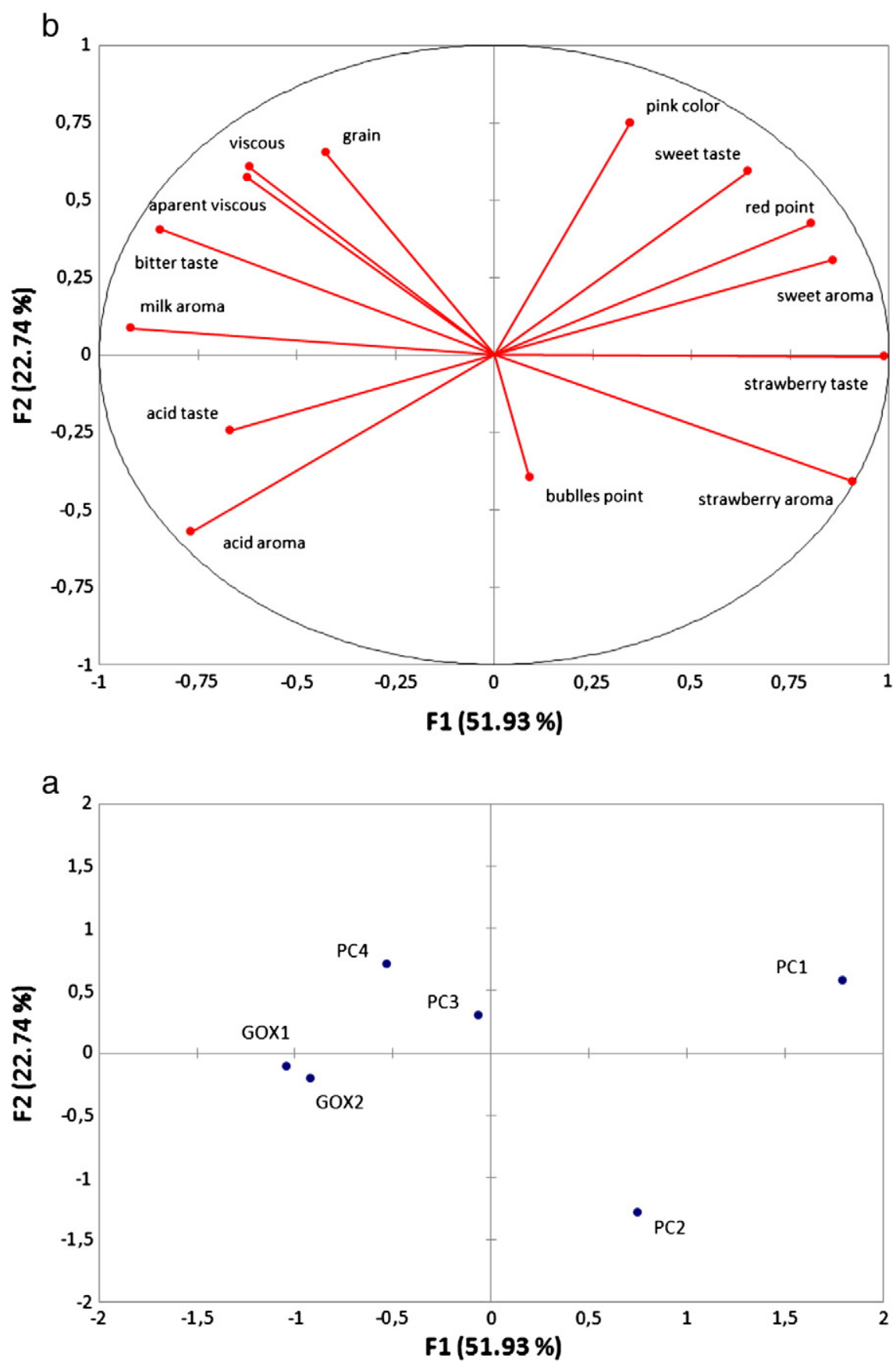

Fig. 3. Representation of the six strawberry probiotic yogurts (b) and the terms used to describe the samples (a), in the first two dimensions of the MFA of data from CATA.

along the Brazilian territory. Therefore, this can guarantee a higher probability of success for yogurts with probiotic glucose oxidase at the consumer market, as gives the opportunity for the producers to modify the formulation, choosing probiotic and lactic culture with adequate metabolic activity, adequate sugar level and other topics.

Consumers used on average three to four terms to describe the yogurts in both methodologies. Viscosity and acid taste were the terms most commonly cited with 92 and 94 and 65-63 citations, respectively, for sorting and napping. In the case of sorting, there was on average 1-3 groups with approximately $80 \%$ of the consumers formed in one group containing only the prototypes GOX1 and GOX2. The ability to discriminate while using sorting and napping has been observed in other food matrices like apples and cheese (Nestrud \& Lawless, 2010), milk chocolates (Kennedy \& Heymann, 2009), perfumes (Veramendi, Herencia, \&
Ares, 2013), high alcohol products (Louw et al., 2013), granola bars (Kennedy, 2010) and beers (Lelièvre, Sylvie Chollet, Abdi, \& Valentin, 2008) and even reduced-calorie biscuit packaging (Carrillo, Varela, \& Fiszman, 2012a, 2012b). Recently napping was used at a cross cultural study covering green tea products with Korean and French consumers (Kim, Jombart, Valentin, \& Kin, 2013).

For CATA (Fig. 3,a,b), five to six terms - of a total of fifteen terms presented to consumers - were used for describing the yogurts: pink color and presence of bubbles, with 45 and 46 citations, respectively. The yogurt PC1 was characterized by the attributes pink color, red point, sweet aroma and sweet taste while PC2 was characterized by the presence of bubbles and strawberry aroma, respectively. The yogurts GOX1, GOX2, PC3 and PC4 were characterized by acid taste, milk aroma, bitter taste, presence of grains and viscosity. A significant difference existed 

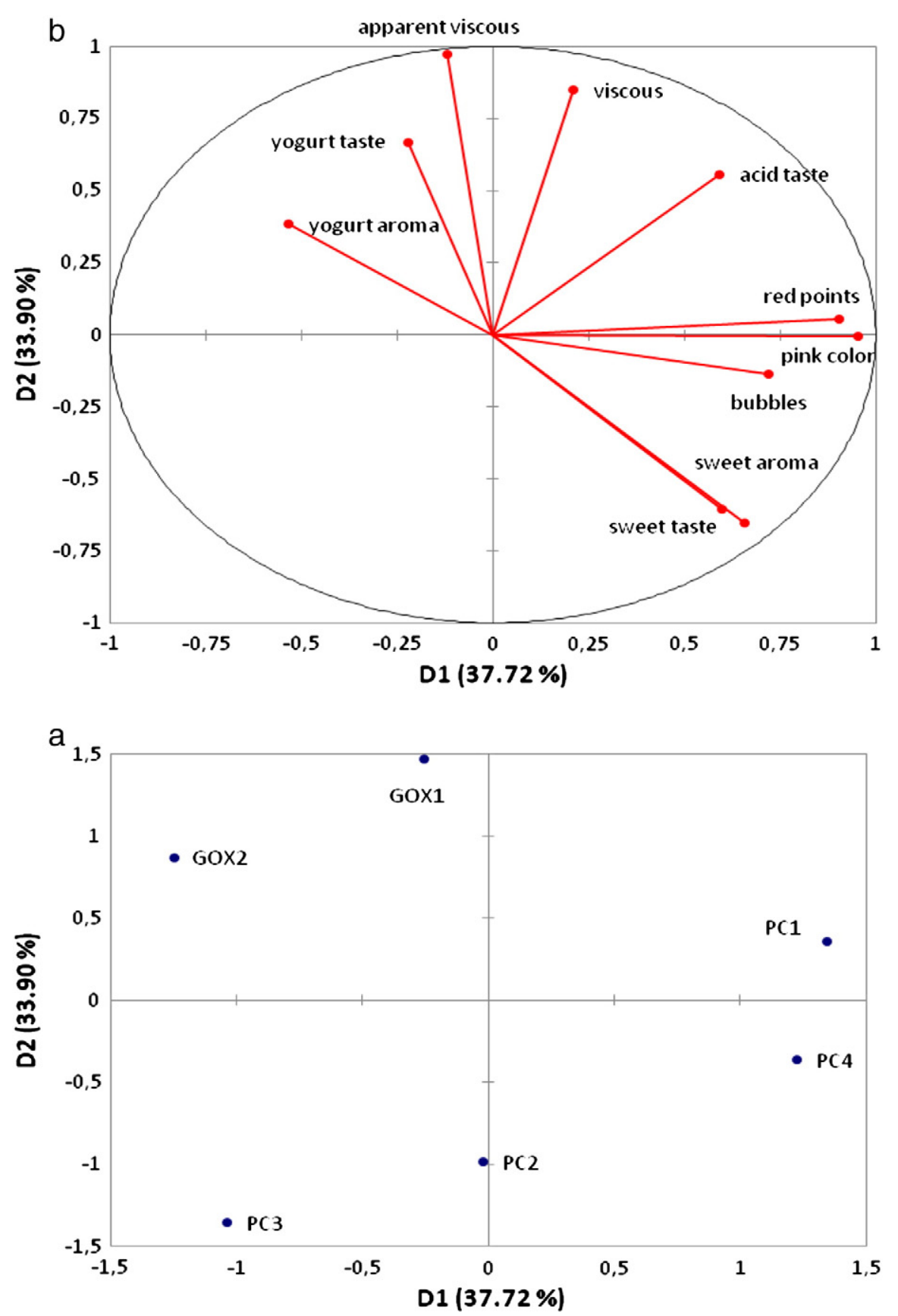

Fig. 4. Representation of the six strawberry probiotic yogurts and the terms used to describe the samples in the first two dimensions of PCA of data from intensity scales.

among the frequency of mention of the attributes using the Friedman test $(p<0.05)$ suggesting that this methodology was capable of detecting the different sensory stimuli provoked by the yogurts. Similar results were observed for ice-creams (Dooley, Lee, \& Meullenet, 2010), chocolate desserts (Ares, Barreiro, Deliza, Gimenez, \& Gámbaro, 2010c), orange drinks (Varela et al., 2010) and aqueous solutions of potassium chloride/sodium chloride (Sinopolli \& Lawless, 2012), orange juices (Lee, Findlay, \& Meullenet, 2013), strawberry cultivars from a breeding program (Lado, Vicente, Manzzioni, \& Ares, 2010) as well as commercial antiaging creams (Parente, Manzoni, \& Ares, 2011) and cosmetic emulsions (Parente, Ares, \& Manzoni, 2010).

Finally, the use of intensity scales resulted in an explanation of $71.62 \%$ in the variability of the two dimensions of the main components (Fig. 4) and the commercial yogurts PC4 and PC1 were characterized by the attributes sweet taste, sweet aroma, strawberry aroma, pink color, presence of bubbles, red points and acid taste; the yogurts GOX1 and GOX2 were characterized by the attributes yogurt taste, yogurt aroma, apparent viscous and viscous. For this methodology, there was a significant difference for all the assessed attributes after ANOVA $(p<0.05)$, suggesting that the chosen attributes were appropriate for characterizing the yogurts, although a clear heterogeneity was seen in the attribute scores that presented large variation among the samples. This is justified by the lack of training and references that are normally present when this methodology is used, especially in QDA (Lawless \& Heymann, 2010).

Since the used methodologies have different fundamentals - in the case of napping and sorting they are holistic methodologies where consumers make the assessment of the product only generally, and CATA and intensity scales trust pre-established attributes determined previously by descriptive studies. Clearly the presence of glucose oxidase changed the sensory perception of the prototype yogurts, making them different 
a

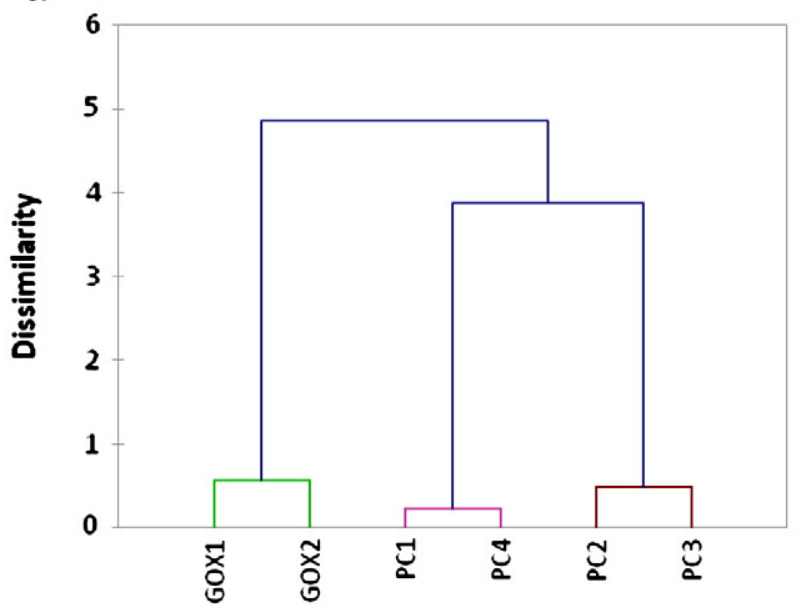

C

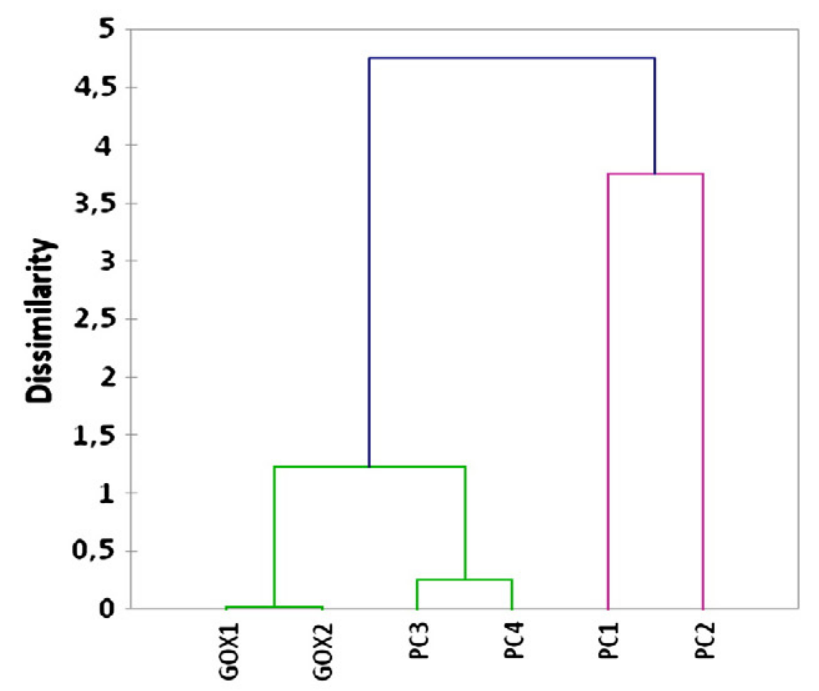

b

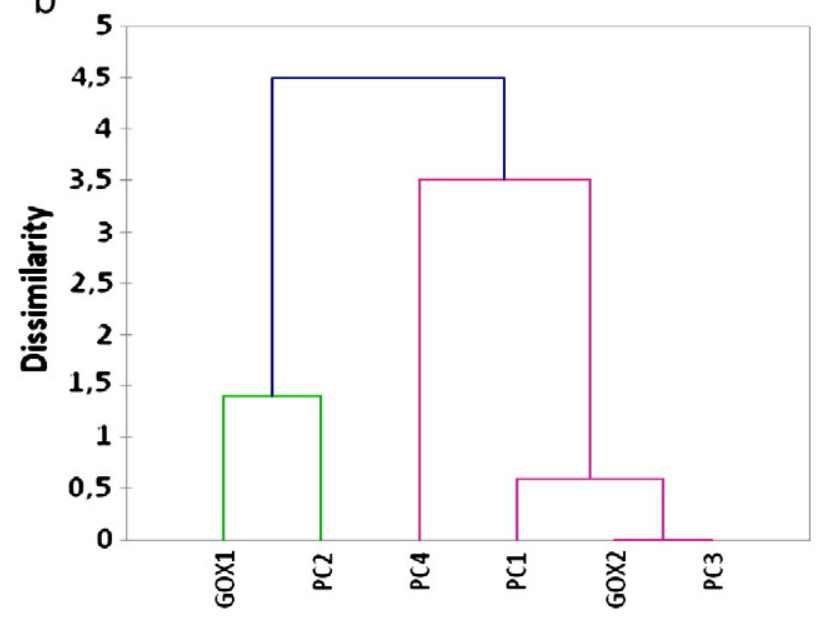

d

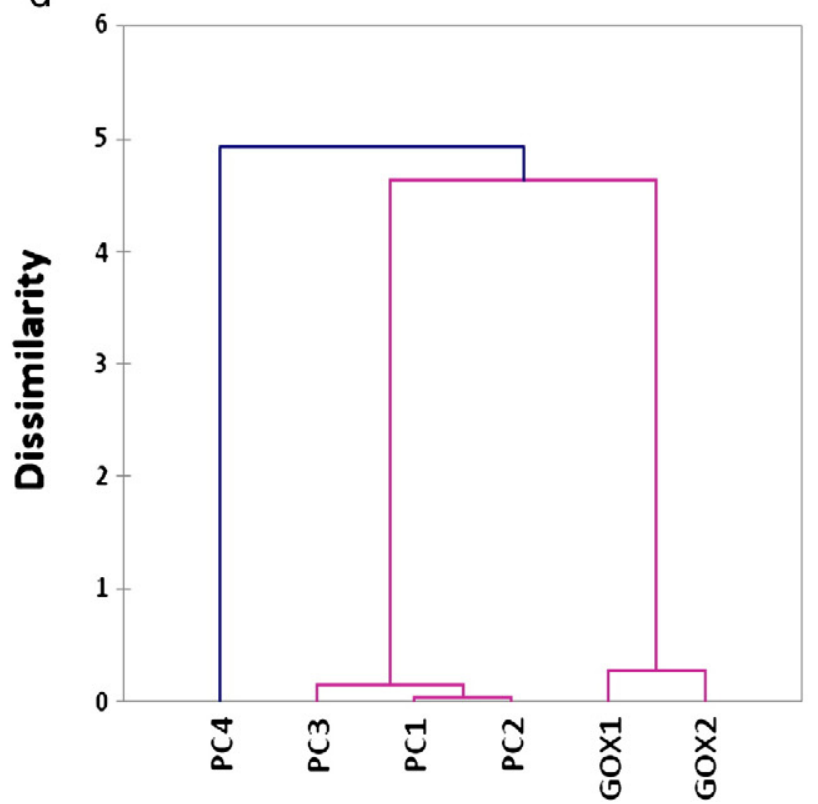

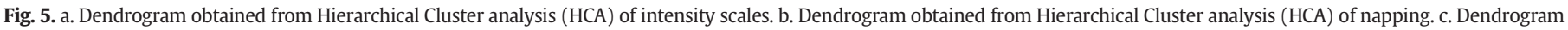
obtained from Hierarchical Cluster analysis (HCA) of CATA. d. Dendrogram obtained from Hierarchical Cluster analysis (HCA) of sorting.

from the commercial brands, which may be explained by the intense production of organic acids by the probiotic bacteria and more intense proteolysis, which may be caused by the release of bitter hydrophobic peptides, as reported recently (Cruz et al., 2012a; Cruz et al., 2013).

\subsection{Comparison of the sensory methods}

Fig. 6 compares the distribution of six probiotic yogurts according to sensory methodology. Each sample is represented by different colors. The different positions show clear differences among the samples, suggesting the consumers were able to differentiate the commercial and prototype yogurts. When $\mathrm{Rv}$ is used for comparing many panels, the best similarities occurred between CATA and sorting and scale (Rv equal to 0.682 and 0.663 , respectively) and between sorting and scale (Rv equal to 0.683 ) while the worst similarities were between napping and the other three methodologies (Rv equal to $0.335,0.427$ and 0.482 for CATA, sorting and descriptive scale, respectively).

While an appropriate correlation is already expected between CATA and the descriptive scale since both methodologies are based on the same principle, that is, both use preselected attributes, the good performance of sorting may be related to the set of samples used, since yogurt has many sensory attributes that interact, leading consumers naturally to use many sensory attributes (texture, taste, aroma) for the formation of groups and description of samples (Moussaoui \& Varela, 2010). Additional studies should assess the performance of sorting variations, such as offering a list of attributes to help consumers to form groups (Chollet, Lelièvre, Abdi, \& Valentin, 2011) and obtain taxonomic sorting (Courcoux, Qannari, Taylor, Buck, \& Greenhoff, 2012).

The low performance of projective mapping may be related to many reasons, namely: (a) the attributes cited by the tasters were not contemplated in the CATA questionnaire and in the intensity scales; (b) the difficulty of performing the activity by the tasters reflected by the excessive amount of time they took to perform it (12 to $15 \mathrm{~min}$ ) in detriment to the time spent on sorting, CATA and descriptive scales (on average $7 \mathrm{~min}$ ). This may have resulted in low concentration and interest in performing the activity, compromising its efficiency (Ares, Deliza, Barreiro, Giménez, \& Gámbaro, 2010a); and finally, (c) the intrinsic nature of the activity, where it is suggested that the process of positioning the samples obeys two phases: the second phase is a more detailed and 


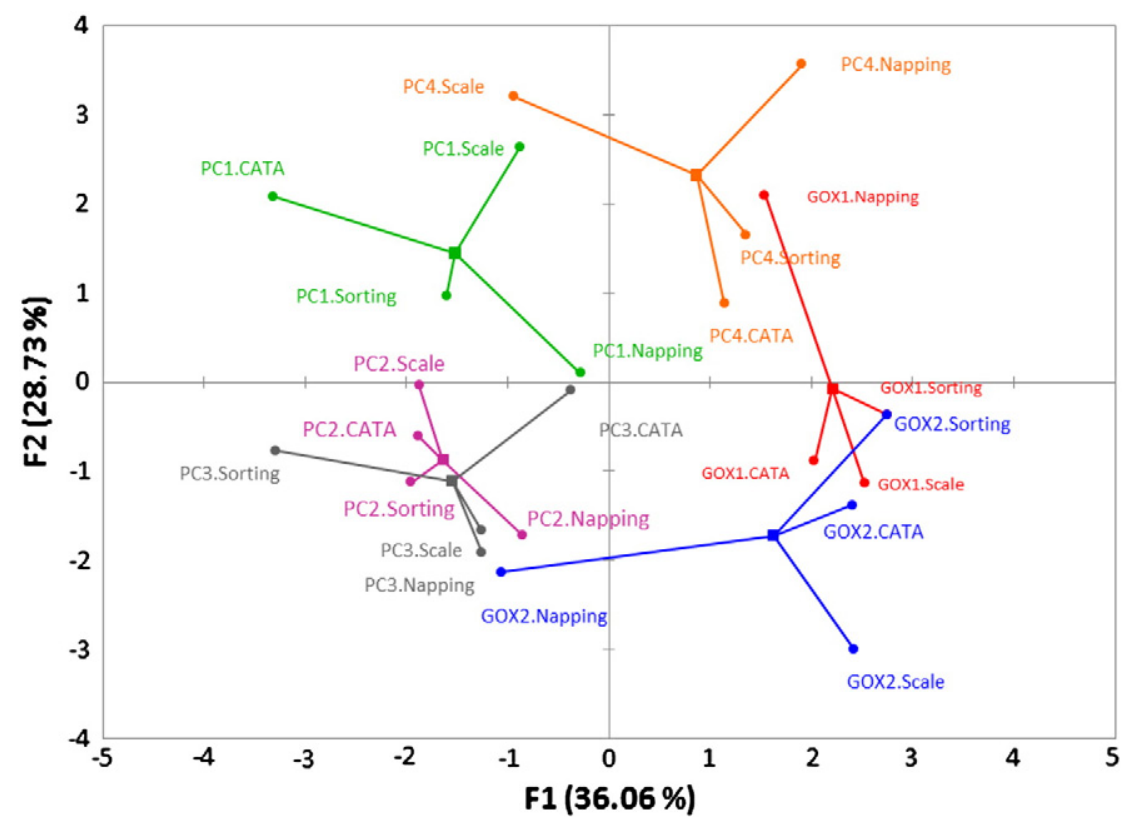

Fig. 6. Comparative MFA on individual configurations of sorting, napping, CATA count and intensity scales of the probiotic yogurts.

refined analysis of the positioning of the samples, so possible changes in their positions occur, which would directly influence the final configuration (Veinand, Godefroy, Adam, \& Delarue, 2011).

Table 2 shows the vocabulary obtained by the sorting and napping task. Overall, sorting seems to have a better description about the attributes related to the yogurts, being observed a total of ten attributes in opposition to just eight attributes obtained in sorting. As example, the attribute appearance was described in sorting by three sensory descriptors, heterogeneous, liquid and pink color while in napping only the sensory descriptor grain was generated.

The results suggest that descriptive sensory methodologies using consumer perceptions, especially sorting and intensity scale can be used for the development of food matrices with multivariate profiles from the sensory point of view, such as probiotic yogurts, and for obtaining a generalized sensory profiling of the product as these methodologies proportionated a total separation of probiotic from commercial yogurts. This can be very interesting for small and medium-sized dairies which often have yogurt as their main product and do not have the financial resources for recruiting and training a sensory panel for the development of a sensory profile via QDA (Bruzzone, Ares, \& Giménez, 2013). They may get valuable information through the use of these methodologies.

However, other sensory techniques such comment analysis (Galmarini, Symoneaux, Chollet, \& Zamora, 2013; Lawrence et al., 2013; Symoneaux, Galmarini, \& Mehinagic, 2012) and free listing (Hough \& Ferraris, 2010; Libertino, Ferraris, Orsonio, \& Hough, 2012) should also be when a more complete assessment is desired as well as

Table 2

Vocabulary of sorting and napping.

\begin{tabular}{lll}
\hline Attributes & Sorting & Napping \\
\hline Appearance & Heterogeneous & Grain \\
& Liquid & \\
Pink color & \\
Aroma & Strawberry & Yogurt \\
& Acid & Strawberry \\
Taste & Sweet & Bitter \\
& Strawberry & Acid \\
& Residual & Yogurt \\
& Yogurt & Strawberry \\
Texture & Viscous & Viscous \\
\hline
\end{tabular}

the partial napping and partial sorting (Dehlholm, Brockhoff, Meinert, Aaslyng, \& Bredie, 2012) and the effect of the information allied to these methodologies (Vidal, Barreiro, Gómez, Ares, \& Gimenez, 2013).

In the specific case, probiotic yogurts with added glucose oxidase, characterized by the sensory descriptors pink color, strawberry taste, acid aroma, yogurt aroma and yogurt taste, and apparent viscous an improved similarity with commercial probiotic yogurts necessarily require the use of lactic and probiotic cultures with moderate metabolic capacity for reducing the acidity and achieving greater control of proteolysis in the final product, keeping the gel more consistent. Appropriate thickeners/stabilizers for optimizing the viscosity of the product may also be used. They have direct influence on texture, which is a relevant parameter for yogurts and has been object of investigation in recent studies (Antmann et al., 2011; Ares, Budelli, Bruzzone, Gímenez, \& Lema, 2011a).

\subsection{Limitations of this study}

In this moment, is a prudent comment about the limitation of this research. Firstly, we used a small consumer panel - just thirteen people while some researches use fifteen consumers at least. Other important topic is the use of the same consumer panel to perform the different methodologies; perhaps they get used with the samples along the experiment and memorized the products, which influenced the low Rvs observed in the experiment. However, it is important to relate that different 3 digit number codes were used in each cup for each methodology. Other important topic is the absence of the results obtained in this study with a sensory profiling obtained by a trained panel using QDA, which would give better consistency for the results obtained. Future studies are needed to confirm this information.

\section{Conclusion}

Sensory methodologies based at the consumer perception may be used in the initial stage of development of food matrices with multiple sensory characteristics, such as probiotic yogurts, especially sorting and intensity scales because of their ease of use, simplicity and ease of understanding by the consumer. In particular, improvement of prototype yogurt added of glucose oxidase in a sensory point of view necessarily 
requires the decrease of the acid and bitter tastes, presence of grains and viscosity of the product.

Our results are interesting especially for small and medium-sized manufacturers that do not have the administrative and financial infrastructure to hire a trained panel for each one of their products. Future studies should include a comparison of the results obtained from a trained panel using descriptive quantitative analysis. They should also include assessment of other sensory methodologies that investigate consumer perception, such as comment analysis and free listing. Additionally, a hedonic test covering a large consumer panel - at least 120 consumers - should also be done with the typical consumers of the product.

\section{References}

Allgeyer, L. C., Miller, M. J., \& Lee, S. -Y. (2010). Sensory and microbiological quality of yogurt drinks with prebiotics and probiotics. Journal of Dairy Science, 93, 4471-4479.

Annuziata, A., \& Vecchio, R. (2013). Consumer perception of functional foods: A conjoint analysis with probiotic. Food Quality and Preference, 28, 348-355.

Antmann, G., Ares, G., Varela, P., Salvador, A., Coste, B., \& Fiszman, S. M. (2011). Consumer's creaminess concept perception: A cross cultural study in three Spanish-speaking countries. Journal of Texture Studies, 42, 50-60.

Ares, G., Barreiro, C., Deliza, R., Gimenez, A., \& Gámbaro (2010a). Application of check all that apply question to the development of chocolate milk desserts. Journal of Sensory Studies, 25, 67-86.

Ares, G., Budelli, E., Bruzzone, F., Gímenez, A., \& Lema, P. (2011a). Consumers' texture perception of milk desserts: Relation with rheological measurements. Journal of Texture Studies, 43, 203-213.

Ares, G., Deliza, R., Barreiro, C., Giménez, A., \& Gámbaro, A. (2010b). Comparison of two sensory profiling techniques based on consumer perception. Food Quality and Preference, 21, 417-426.

Ares, G., Giménez, A., Barreiro, C., \& Gámbaro, A. (2010c). Use of an open-ended question to identify drivers of liking of milk desserts. Comparison with preference mapping techniques. Food Quality and Preference, 21, 286-294.

Ares, G., Varela, P., Rado, G., \& Gimenez, A. (2011b). Are consumer profiling techniques equivalent for some product categories? The case of orange-flavoured powdered drinks. International Journal of Food Science and Technology, 46, 1600-1608.

Ares, G., Varela, P., Rado, G., \& Giménez, A. (2011c). Identifying ideal products using three different consumer profiling methodologies. Comparison with external preference mapping. Food Quality and Preference, 22, 581-591.

Bruzzone, F., Ares, G., \& Giménez, A. (2012). Consumers' texture perception of milk desserts II - Comparison with trained assessors' data. Journal of Texture Studies, 43, 214-226.

Bruzzone, F., Ares, G., \& Giménez, A. (2013). Temporal aspects of yoghurt texture perception. International Dairy Journal, 29, 124-134.

Cadena, R. S., Cruz, A. G., Faria, J. A. F., \& Bolini, H. M.A. (2012). Reduced fat and sugar vanilla ice creams: Sensory profiling and external preference mapping. Journal of Dairy Science, 95, 4842-4850.

Carrillo, E., Varela, P., \& Fiszman, S. (2012a). Packaging information as a modulator of consumers' perception of enriched and reduced-calorie biscuits in tasting and non-tasting tests. Food Quality and Preference, 25, 105-115.

Carrillo, E., Varela, P., \& Fiszman, S. (2012b). Effects of food package information and sensory characteristics on the perception of healthiness and the acceptability of enriched biscuits. Food Research International, 48, 209-216.

Chollet, S., Lelièvre, Abdi, H., \& Valentin, D. (2011). Sort and beer: Everything you wanted to know about the sorting task but did not dare to ask. Food Quality and Preference, 22, 507-520.

Courcoux, P., Qannari, E. M., Taylor, Y., Buck, D., \& Greenhoff, K. (2012). Taxonomic free sorting. Food Quality and Preference, 23, 30-35.

Cruz, A. G., Cadena, R. S., Faria, J. A. F., Bolini, H. M.A., Dantas, C., Ferreira, M. M. C., et al. (2012a). PARAFAC: Adjustment for modeling consumer study covering probiotic and conventional yogurt. Food Research International, 41, 211-215.

Cruz, A. G., Cadena, R. S., Faria, J. A. F., Oliveira, C. A. F., Cavalcanti, R. N., Bolini, M. H. A., et al. (2011). Consumer acceptability and purchase intent of probiotic yoghurt with added glucose oxidase using sensometrics, artificial neural networks and logistic regression. International Journal of Dairy Technology, 64, 549-556.

Cruz, A. G., Castro, W. F., Faria, J. A. F., Bogusz, S., Jr., Granato, D., Celeguini, R. M. S., et al. (2012b). Glucose oxidase: A potential option to decrease the oxidative stress in stirred probiotic yogurt. $L W T$ - Food Science and Technology, 47, 512-515.

Cruz, A. G., Castro, W. F., Faria, J. A. F., Bolini, H. M.A., Celeguini, R. M. S., Raices, R. S. L., et al. (2013a). Stability of probiotic stirred yogurt added with glucose oxidase in different packaging materials along the refrigerated storage. Food Research International, 51, 723-728.

Cruz, A. G., Castro, W. F., Faria, J. A. F., Lollo, P. C. B., Amaya-Farfan, J., Freitas, M. Q., et al. (2012c). Probiotic yogurts manufactured with increased glucose oxidase levels: Postacidification, proteolytic patterns, survival of probiotic microorganisms, production of organic acid and aroma compounds. Journal of Dairy Science, 95, 2261-2269.

Cruz, A. G., Cavalcanti, R. N., Guerreiro, L. M. R., Sant'Ana, A. S., Nogueira, L. C., Oliveira, C. A. F., et al. (2013b). Developing a prebiotic yogurt: Rheological, physico-chemical and microbiological aspects and adequacy of survival analysis methodology. Journal of Food Engineering, 114, 323-330.
Cruz, A. G., Faria, J. A. F., Walter, E. H. M., Andrade, R. R., Walter, E. H. M., Cavalcante, R. N., et al. (2010). Processing optimization of probiotic yogurt containing glucose oxidase using response surface methodology. Journal of Dairy Science, 93, 5059-5068.

Dehlholm, C., Brockhoff, P. B., Meinert, L., Aaslyng, M.D., \& Bredie, W. L. P. (2012). Rapid descriptive sensory methods - Comparison of free multiple sorting, partial napping, napping, flash profiling and conventional profiling. Food Quality and Preference, 26, 267-277.

Dooley, L., Lee, Y. -S., \& Meullenet, J. -F. (2010). The application of check-all-that-apply (CATA) consumer profiling to preference mapping of vanilla ice cream and its comparison to classical external preference mapping. Food Quality and Preference, 21, 394-401.

Ferdouse, R., Rouhi, M., Mohammadi, Mohamad, Mortazavian, A.M., Khosravi-Darani, K., \& Rad, A. H. (2013). Evaluation of probiotic survivability in yogurt exposed to cold chain interruption. Iranian Journal of Pharmaceutical Research, 12, 139-144.

Galmarini, M. V., Symoneaux, R., Chollet, S., \& Zamora, M. C. (2013). Understanding apple consumers' expectations in terms of likes and dislikes. Use of comment analysis in a cross-cultural study. Appetite, 62, 27-33.

Gomes, A. A., Cruz, A. G., Cadena, R. S., Faria, J. A. F., Carvalho, C. C., Lollo, P. C., et al. (2011). Effect of the inoculation level of $L$. acidophilus in probiotic cheese on the physicochemical features and sensory performance towards commercial cheeses. Journal of Dairy Science, 94, 4777-7786.

Gonzalez, N. J., Adhikari, K., \& Sancho-Madriz, M. F. (2011). Sensory characteristics of peach-flavored yogurt drinks containing prebiotics and synbiotics. LWT - Food Science and Technology, 44, 158-163.

Granato, D., Branco, G. F., Cruz, A. G., Faria, J. A. F., Faria, J. A. F., \& Shah, N.P. (2010). Probiotic dairy products as functional foods. Comprehensive Reviews in Food Science and Food Safety, 9, 455-470

Hough, G., \& Ferraris, D. (2010). Free listing: A method to gain initial insight of a food category. Food Quality and Preference, 21, 295-301.

Huertas, R. A. P. (2012). Yogurt en la salud humana. Revista Lasallista de Investigacion, 9, $162-177$

Kennedy, J. (2010). Evaluation of replicated projective mapping of granola bars. Journal of Sensory Studies, 25, 672-684

Kennedy, J., \& Heymann, H. (2009). Projective mapping and descriptive analysis of milk and dark chocolate. Journal of Sensory Studies, 24, 220-233.

Kim, Y. -K., Jombart, L., Valentin, D., \& Kin, K. -O. (2013). A cross cultural study using napping: Do Korean and French consumers perceive various green tea products differently. Food Research International, 53, 534-542.

Lado, J., Vicente, E., Manzzioni, A., \& Ares, G. (2010). Application of a check-all-that-apply question for the evaluation of strawberry cultivars from a breeding program. Journal of the Science of Food and Agriculture, 90, 2268-2275.

Lawless, H. T., \& Heymann, H. (2010). Sensory evaluation of food. Principles and practices (2nd ed.)New York: Springer.

Lawrence, G., Symoneaux, R., Maitre, I., Brossaud, F., Maestrojuan, M., \& Mehinagic, E. (2013). Using the free comments method for sensory characterisation of Cabernet Franc wines: Comparison with classical profiling in a professional context. Food Quality and Preference, 30, 145-155.

Lee, Y., Findlay, C., \& Meullenet, J. -F. (2013). Experimental consideration for the use of check-all-that-apply questions to describe the sensory properties of orange juices. International Journal of Food Science and Technology, 48, 215-219.

Lelièvre, M., Sylvie Chollet, S., Abdi, H., \& Valentin, D. (2008). What is the validity of the sorting task for describing beers? A study using trained and untrained assessors. Food Ouality and Preference, 19, 697-703.

Libertino, L., Ferraris, D., Orsonio, M. M. L., \& Hough, G. (2012). Analysis of data from a free-listing study of menus by different income-level populations. Food Quality and Preference, 24, 269-275.

Louw, L., Malherbe, S., Naes, T., Lambrechts, M., Van Rensburg, P., \& Nieuwoudt, H. (2013). Validation of two Napping® techniques as rapid sensory screening tools for high alcohol products. Food Quality and Preference, 30, 192-201.

Lucey, J. A. (1998). Cultured dairy products: An overview of their gelation and texture properties. International Journal of Dairy Technology, 57, 77-84.

MacFie, H. J., Bratchell, N., Greenhoff, K., \& Vallis, L. V. (1989). Designs to balance the effect of order of presentation and first-order carry-over effects in hall tests. Journal of Sensory Studies, 4, 129-148.

Moraes, P. C. B. T., \& Bollini, H. M.A. (2010). Perfil sensorial de iogurtes comerciais sabor morango nas versões tradicional e light. Brazilian Journal of Food Technology, 13, $112-119$

Moussaoui, K. A., \& Varela, P. (2010). Exploring consumer product profiling techniques and their linkage to a quantitative descriptive analysis. Food Quality and Preference, 21, 1088-1099.

Nestrud, M.A., \& Lawless, H. T. (2010). Perceptual mapping of apples and cheeses using projective mapping and sorting. Journal of Sensory Studies, 25, 390-405.

Parente, M. E., Ares, G., \& Manzoni, A. V. (2010). Applicatin of two consumer profiling techniques to cosmetic emulsions. Journal of Sensory Studies, 25, 685-705.

Parente, M. E., Manzoni, A. V., \& Ares, G. (2011). External preference mapping of commercial antiaging creams based on consumers' responses to a check-all-that-apply question. Journal of Sensory Studies, 26, 158-166.

Saint-Eve, A., Lévy, C., Martin, N., \& Souchon, I. (2006). Influence of proteins on the perception of flavored stirred yogurts. Journal of Dairy Science, 89, 922-933.

Sinopolli, D. A., \& Lawless, H. T. (2012). Taste properties of potassium chloride alone and in mixtures using sodium chloride using a check-all-that-apply method. Journal of Food Science, 77, 319-322.

Symoneaux, R., Galmarini, M. V., \& Mehinagic, E. (2012). Comment analysis of consumer's likes and dislikes as an alternative tool to preference mapping. A case study on apples. Food Quality and Preference, 24, 59-66. 
Valentin, D., Chollet, S., Lelievre, M., \& Abdi, H. (2012). Quick and dirty but still pretty good: A review of new descriptive methods in food science. International Journal of Food Science and Technology, 47, 1563-1578.

Varela, P., \& Ares, G. (2012). Sensory profiling, the blurred line between sensory and consumer science. A review of novel methods for product characterization. Food Research International, 48, 893-908.

Varela, P., Ares, G., Gimenez, A., \& Gambaro, A. (2010). Influence of brand information on consumers' expectations and liking of powdered drinks in central location tests. Food Quality and Preference, 21, 873-880.
Veinand, B., Godefroy, C., Adam, C., \& Delarue, J. (2011). Highlight of important product characteristics for consumers. Comparison of three sensory descriptive methods performed by consumers. Food Quality and Preference, 22, 474-485.

Veramendi, M., Herencia, P., \& Ares, G. (2013). Perfume odor categorization: To what extent trained assessors and consumers agree? Journal of Sensory Studies, 28, 76-89.

Vidal, L., Barreiro, C., Gómez, B., Ares, G., \& Gimenez, A. (2013). Influence of information on consumers' evaluations using check-all-that-apply questions and sorting: A case study with milk desserts. Journal of Sensory Studies, 28, 125-137. 